\title{
Authentic Assessment and Evaluation: Paramount Means for the Maximization of Teaching and Learning
}

\author{
Mary Dorette Okoye
}

Queen of Apostles Seminary, Afaha-Obong, Abak, Akwa Ibom State, Nigeria

Doi:10.5901/jesr.2014.v4n7p31

\begin{abstract}
The rate of poor performance of students in Senior School Certificate of Education (SSCE), or in West African Education Certificate (WAEC) is quite alarming. Additionally, the poor performance of so many graduates in teaching profession is quite disturbing. I have heard many teachers exclaimed: "how did this or these student(s) arrive at senior class levels?" As a teacher in senior school level, I have also observed several students who could not make headway at senior level. I began to wonder whether they pass any of their primary and junior secondary classes at all. My greatest shock came when I was involved in an interview of a graduate with degree in Mathematics, Computer Science and Engineer who applied for a teaching post for Senior Secondary School I through III Mathematics. I was asked to set questions for both written and oral interview for him/her. I decided to set questions based on SSS I - III syllabus since he/she was to teach those classes, but was shocked that he/she could not attempt any of the questions except for a few in Junior class level. I was perplexed on what could be the cause. Among the responses that came to my head were lack of proper Assessment and Evaluation (A\&E) of students on the part of teachers in the previous classes, exam malpractice or expo and lack of proper supervision in the exam hall, parents' and peer pressure and students' "false" ambitions. In this dilemma, I wish to begin with a phrase from Socrates. He believed that the "unexamined life is not worth living for man" or woman. Similarly, the art of teaching and learning without regular and authentic A\&E is a useless or aimless exercise. Authentic A\&E are unattainable in a situation where there is no good plan and implementation of general and specific curriculum outcomes and regular supervision of teachers and students. They are not realizable where there are bundles of teachers or educators that are not proficient in the teaching and learning process. Authentic assessment/evaluation is possible where teachers make use of good assessment strategies and tools. Every teacher or student needs improvement or growth because life is never static, but dynamic. In the Nigeria's context and elsewhere, it can never be over emphasized that the issue of authentic A\&E should be seen as indispensible measures for the maximization and high productivity in teaching and learning. Due to the page limit of this work, the issue of parents'/peer pressure and students' "false" ambitions is beyond the scope of this work. For this reason, this paper will explores the concepts, purpose, goals, types, importance, methods, etc of assessment and evaluation. Finally, the author makes some recommendations for effective practice of assessment and evaluation at all levels of education but especially in primary, secondary, and tertiary institutions for greater promotion of teaching and learning.
\end{abstract}

\section{Introduction}

As already stated above, the "unexamined life is not worth living for man" ascertained by Socrates. Similarly, the art of teaching and learning without regular and authentic A\&E is a useless or aimless exercise. A business man or woman at the end of a day's or week's transactions takes stock of his/her business. He/she checks to see if any gain or loss was incurred. An actor or actress examines, after his/her performance, how he/she has performed and takes note of the progresses as well as mistakes and criticisms made by others in order to improve in future. The same examination is required in all professional sphere including teaching and learning. The issue of poor performance will continue to escalate if authentic A\&E of both students and teachers is not seriously taken. In every nation, there is need for authentic assessment/evaluation if true teaching and learning will thrive. Every nation dreams of proficient educators, wise and intelligent students. These dreams are possible thru authentic (A\&E). In some of the institutions both higher and lower levels in our country Nigeria, it is obvious that not all the assessment and evaluation results are trustworthy or genuine due to some improper ways of assessing and evaluating, exam malpractices or falsification of marks or grades on the parts of some teachers, lecturers or professors. This is very detrimental to teaching and learning, to students and to the nation at large because bundles of "idiots" will be produced at the end of the day. The economic growth will be affected drastically because those students who graduated thru sorting or exam malpractice do not perform or defend what they claimed to be. Consequently, they will be expelled or be terminated from their employments. The outcome will be seeking for "alternative" way of surviving or getting one's daily bread which may involve stealing, kidnapping, drinking, smoking or 
drug abuse, frustration and the like.

In the Nigeria's context and elsewhere, the issues of Assessment and Evaluation (A \& E) should be seen as indispensible measures for the maximization and high productivity in teaching and learning. The Nigerian National Policy on Education (2004) section 11 states that educational services should aim at developing, assessing, and improving educational programs. They should focus on enhancing teaching and improving the competence of teachers, promoting in-service training in order to make learning experiences more meaningful to their students. I strongly believe that the goals of educational services stated above (improving educational programs and teachers' competence, enhancing teaching in order to help students have more meaningful learning experiences) can be realized thru regular and authentic assessment of teachers themselves in their teaching profession. Learning experiences also can be more meaningful to students when they are appropriately taught, well engaged, properly assessed and evaluated by competent teachers. An incompetent teacher does not know when, what, and how to assess and evaluate his/her students to improve their learning potentials and education. At this point, I think it is appropriate to examine briefly the concept of education according to different authors' viewpoints because one can only assess and evaluate appropriately what he/she knows very well. One can only give a correct answer to a question if he/she knows the correct answer and also knows that it is the correct answer. In the same way, a teacher can properly assess and evaluate teaching and learning if he/she knows correctly what education is, including its objectives and processes.

\subsection{Concept of Education}

Fafunwa (1991) believes that "education is all the aggregates of all the processes by which a person develops abilities, attitudes and other forms of behaviour of positive and meaningful value in the society in which he lives." O'Connor (1957), cited in Ezewu et al (1981), defined education as "the process by which society through schools, colleges, universities and other institutions deliberately transmits its cultural heritage." In Peters (1972) perspective, education is means of initiating young ones into the values of society. M. V. Jeffery (cited in Ezewu) viewed education as a process by which community nurtures personal growth or prepares its members for community living. Gutek (1974), cited in Okafor and Quist (1989), describe education as a "total social processes" by which a person is brought into life in a culture. An outstanding French Sociologist by name Emile Durkheim perceives education as a "systematic socialization of the younger generation by which the latter learn religious and moral beliefs, feelings of nationality and collective opinions of all kinds."

Of all the above descriptions of education, I am in consensus with that of Fafunwa and Durkheim because they are in accord with my own perception of education. Fafunwa described education as "all the aggregates of all the processes by which a person develops..." Unlike O'Connor who sees education as the work of "academic institutions" and Jeffery who sees it as the work of a community, Fafunwa used the terms "all the aggregates of all the processes" to depict that education is not a one man's business. It involves a team work of different collaborators starting with parents in their families or homes, teachers in schools, lecturers and professors in the universities, clergies or pastors in churches, government leaders in societies, and etcetera. Although Durkheim did not specify those that are involved in the education of the "younger generation," he pointed out that they "learn religious and moral beliefs, feelings of nationality and collective opinions of all kinds" showing that many hands were or are on deck for the education of the "younger generation."

In my own view point, education can be described as a procedure by which parents, teachers and adults of the society which include both churches' and governments' leaders inculcate in children and youths of their society (formally and informally) their sound traditions, values and literacy in order to help them develop their innate and acquired gifts, talents, potentials and widening of their horizons in the world for the betterment of the society in which they belong. In other words, education is a process of teaching young persons the right living or how to use their innate and acquired endowments to live well in the present and prepare for better future living which benefits not only oneself, but also others in the one's society. The education discussed above can take place starting from homes, schools, universities, churches, community, and so on.

If education is a process of developing innate and acquired gifts and instilling a nation's culture and developing a child's intellect, aptitudes, attitudes, and other types of excellent and positive characters which enable him/her to live and participate fully in the society in which he/she lives, and be of benefit to others, it is of great importance that students be authentically assessed before, during, and after some periods and finally be evaluated in the process of learning to identify and measure (quantitatively and qualitatively) the content and quality of students' works and what they have been able to absorb or comprehend. In other words to check if students have imbibed the cultural values taught to them; to see 
if they have developed their inherent gifts, intellect, aptitudes, attitudes, good characters that will enable them function properly in the society. As teachers and students are the protagonists in the art of teaching and learning, teachers will assess and evaluate their students' works, their own works, and teaching strategies used in delivering their lessons to help them adjust and improve for better quality teaching and output. Before discussing the concepts of $A \& E$, I would like to specify that although this paper deals with authentic $A \& E$, more emphasis will be laid on assessment than evaluation due to the nature and page limit of this paper. It might be reasonable to ask the following questions at this point. When is an assessment authentic? In other words, what makes an assessment to be authentic?

\section{2 "Authentic" Assessment}

The answers are not far-fetched. The word "authentic" was used to disqualify a "fake" or an erratic A\&E of students. Assessment is authentic when it is in line with the curriculum outcomes or objectives. It must be in the best interest of both teachers and students. That is, every student must benefit positively from it. It must promote both teaching and learning. It must be free of exam mal-practice or "sorting," prejudice and must meet every student's need. Students must have produced genuine or reliable performance tasks of good or excellent quality and received good or dependable feedback from teachers, lecturers, or professors concerned. Hence, I join Copper (2010) cited in Wiggins (1998) to ascertain that authentic assessment must "anchor testing in the kind of work real people do, rather than merely eliciting easy-to-score responses to simple questions.... We thereby learn whether students can intelligently use what they have learned in situations that increasingly approximate adult situations, and whether they can innovate in new situations"'

Furthermore, the term authentic is used to portray the need for the validity and reliability of any A\&E. Hence, assessment is authentic when it is well planned and is accurate; when it has goal or purpose and is in line with teaching, grading, and reporting. It is authentic when it is well balanced. That is, assessment is authentic when it is valid and must have been written, oral tests and performance tasks that may include some actions or demonstrations. It must not be too rigid, but a bit flexible so that every student will experience success and improvement in his/her learning. I am in consensus with Cooper (2010) that flexibility in assessment is necessary to enable teachers to adapt or modify their planned assessment strategies for different reasons such as student with learning disabilities. However, he added that flexibility does not mean that a teacher will not have clear expectations since an authentic teacher should provide his/her students with brief guidelines about assessment. Authentic assessment is regular and informs learning. That is, teachers can assess their students frequently in informal and formal ways by conferencing with them, observing and listening to them, assessing their major tests or projects and analyzing the results. The information gathered can be used to adjust subsequent instruction, address lapses so as to maximize learning for students.

\subsection{Concept of Assessment}

Just as education has varying facets and can vary from nation to nation or culture to culture, assessment can be defined in several ways with different interpretations. According to Cooper (2010), assessment is a mode of "gathering data about student knowledge and / or skills, either through informal methods such as observation, or formal methods such as testing." In my viewpoint, I can delineate assessment as a technique of collecting information from various sources that depicts authentically how well a student is performing or has performed in achieving the general and specific curriculum goals or program's objectives in a stipulated time-frame. It can be defined as a consistent and authentic strategy used in gathering information supported by sufficient evidence regarding a student's learning thru "diagnostic, formative, and summative" assessment. The concepts and importance of the above named assessments will be explained later in this paper. Having discussed the concept of assessment, it is necessary to examine in brief the concept of evaluation since the two are interwoven.

\subsection{Concept of Evaluation}

Different peoples have varying perspectives concerning evaluation. For Cooper, evaluation involves making of "judgments about student-demonstrated knowledge and/or skills." For the University of Toronto Schools, evaluation is "the process of judging the quality of students work on the basis of established criteria, and assigning a value ... to represent that quality." Still, some perceive evaluation as the judgments made by teachers regarding the assessment of student's learning which is focused on the established criteria. The heart of these judgments includes the achievement of curriculum and program goals, expectations, and outcomes, using information gathered by different assessment tools. 
In addition to the exceeding perspectives, evaluation, in my own standpoint, is the process of examining, representing, assessing, judging, and ascertaining the quantity and quality of work a student has accomplished based on an orthodox benchmarks, and allocating values to represent the quantity and quality of the tasks accomplished. The values assigned can be in the form of levels, letter grades, or numerical marks and must be reviewed and approved by the school authority or Board to be very authentic and valid. In the world, nothing happens by chance. Every event has a reason. Hence, assessment and evaluation are not out of place to have their own drive.

\subsection{Purpose and Goals of Assessment/Evaluation}

In general, it is difficult to separate the two terms ("purpose" and "goals") because they seem to have the same connotation. However, there are some few divergences. While the purposes of assessment include finding students' prior knowledge, improving students' learning, and knowing students' new knowledge and achievement within a specified period of time, the goals of assessment must be set with the intention of benefiting students. In other words, assessment must promote students' learning, must avoid preconception, and must be supple so as to meet the students' learning needs. The goals of assessment must lead to students' success in their academics, and must be the fulfilment and endpoint or solution sets to the purpose of assessment. The goal of assessment must include taking a student from where you, the teacher, met him/her and accompany him/her to go as far as he/she could. Above all, the goal of assessment must focus on helping teachers have honest introspection and make proficient and effective decision in their assessment of both students' learning and their teaching.

\subsection{Contrast between Assessment and Evaluation}

In as much as the two terminologies look alike, there exist some variances. Cullen (2012) identifies content, orientation and findings as areas of major differences between assessment and evaluation. Some of the dissimilarities can be seen in the table below:

\author{
Assessment \\ Assessmentputs emphases on learning, teaching and \\ outcomes. \\ It creates a room and offers information for boosting \\ learning and teaching. \\ In terms of content, formative assessment is ongoing \\ and aimed at improving learning process. \\ In orientation, which emphasis measurement, \\ assessment is "process-oriented" \\ In the findings, diagnostic assessment identifies the \\ areas for improvement.
}

\section{Evaluation}

Evaluation lays emphasis on scores, potentials, achievement, behaviours, etc.

It reflects classroom components (classroom discussion, cooperation and oral knack) rather than course content and mastery level.

Evaluation aims at final grades and tries to measure quality and authenticity.

Evaluation is "product-oriented" or deals with what students have learned and are able to do.

Evaluation uses judgment to arrive at overall mark or letter grade.

\section{Types of Assessments}

There are different kinds of assessment. Some of them include diagnostic, formative, and summative assessments. I am of the opinion that diagnostic, formative, and summative assessments are indispensible if a comprehensive, valid, and reliable result of high teaching quality, the students' learning progress or what they have learned and are able to do must be achieved. I also maintain that the three named assessments are very vital in teaching and learning process because of the following reasons that will be enumerated later in the importance of assessment in this paper. Before then I would like to examine in brief the three main types of assessment.

\subsection{Diagnostic Assessment or Assessment for Learning}

Diagnostic assessment is the assessment that is performed at the start of any new topic or unit in order to help the teacher to determine a starting point for the lesson topic. It gives the teacher a clue of students' preceding knowledge and ability towards the new lesson topic. It can also be used at the beginning of already started topic or unit to serve as a review of the previous lesson(s) and knowledge to test what students still retain or remember of the last lesson(s) or topic(s) that was taught in class. McTghe and O'Connor (2005) view diagnostic assessment as "pre-assessments" of the 
previous instruction which helps teachers to understand students' former knowledge and skill levels, identifying students' misconceptions, profile of learners' interests, and reveal the students' favourite learning styles.

\subsection{Formative Assessment or Assessment for Learning}

Formative assessment is an assessment a teacher undertakes regularly during and at the end of a lesson to provide students with frequent information as they progress in their learning, and skills' development. It can be oral test or few minutes writing test to see if students are grasping the lesson concepts and contents. For McTghe and O'Connor, it can also be in the form of ungraded written or oral quizzes, learning log, students' constructed concept map, and so on. Because diagnostic and formative assessments are meant to check students' knowledge and progress in their learning process, teachers are not expected to grade or record their outcomes. In the assessment for learning which consists of diagnostic and formative assessment, students expect to get responses or solutions to the following three questions: "'where are we going?' 'Where are we now?' and 'how do we get there from here?'" (Halifax Regional School Board (HRSB)). I would like to add a $4^{\text {th }}$ and $5^{\text {th }}$ questions: what and what made it possible for us to arrive here? What have we achieved? I will also like to rearrange these questions in the following order or scale of preference: Where are we now? for diagnostic assessment; where are we going and how do we get there from here? for formative assessment; what and what made it possible for us to arrive here, and what have we achieved? for summative assessment.

\subsection{Summative Assessment or Assessment of Learning}

Summative assessment is the assessment that is done at the end of a unit and a course. It provides students an opportunity to synthesize, apply, or demonstrate their learning. Final mark or letter grade is given to students based on their performance. Inother words, summative assessment deals with the students' achievement at the end of a given period. For many people, summative assessments are only associated with "standardized" tests such as district's and state's assessments. For some they are used for standardized tests as well as regional and classroom programs. At district and classroom level, summative assessment is used for grading process. Some examples of summative assessments include class or term projects and presentations, final exams or tests, students' work portfolios, class and performance tasks, State assessments, district benchmark or interim assessments, end-of-unit or semester exams, scores that are used for accountability of schools and students (Garrison and Ehringhaus).

Having discussed about different types of assessment, it might make sense at this juncture to make this interrogation: Must diagnostic, formative, and summative assessments be present for effective teaching and learning to occur? My simple answer is yes because they are of great importance. Some reasons can be found in the importance of assessment enlisted as follows:

\subsection{Importance of Assessment}

As already specified earlier, diagnostic, formative, and summative assessments are inevitable in the teaching and learning process because without diagnostic assessment or pre-test, a teacher will not know what students already know and are capable of doing. As a result, a teacher will not know where and how to begin, what to skip or what to elaborate more, what and where to differentiate, or adapt his/her lesson.

Without formative assessment, a teacher will not know how students are progressing or have improved or where students are in relative to the learning targets or standards. Students also will not know how they are doing, where they need to focus and how to move to the next stage of their learning. In addition, the teacher will not know where to make adjustment, differentiate instruction, or where and how to intervene in order to help students succeed.

Without summative assessment, a teacher is not $100 \%$ sure of where student are in relation to the curriculum learning outcomes. He/she cannot justify how much students have learned and what they can do or which skills were acquired. Assessment cannot be completed without proper and comprehensive evaluation. Evaluation helps both teachers and school administrators to make plans for school programs including the manner of administering those programs. It helps them to make decision on the day to day running of those programs including teaching and learning and how to improve those programs for the good of students.

For Cooper (2010), two main functions or importance of assessment areas follows: firstly, assessment informs instruction, and communicates information about achievement. Thus, in the assessment for learning which comprises of diagnostic and formative assessment, the teacher is notified about students' previous knowledge and current aptitude. 
The teacher makes the necessary adjustments to accommodate all students and provide them with feedbacks about their improvement as teaching and learning progress.

Secondly, assessment informs students and their parents how much students have learned or accomplished within a stipulated time frame. In the summative assessment, teacher judges the quantity and quality of the students' works, and uses achievement levels or letter grades to describe the quantity and quality of the work. In overall, a good assessment/evaluation will help to produce the best teachers, farmers, doctors, lawyers, engineers, musicians, artists, etc. for the nation's future consumption.

Notwithstanding the importance of the three kinds of assessment, I have a preference among them. In my acuity, I would argue that diagnostic assessment is the most important of the three because it provides a good opportunity for both students and teachers to have a good beginning. Thus, when you start well with a good and solid foundation, there is 90 percent chance of having a happy and good ending. An adage stated that he/she, who did not know where the rain started to beat him/her, will not know where it stopped beating him/her as well. If you do not know where and how you began, you would not know what to look for in progression and what to judge at the end. Consequently, without diagnostic assessment, you can't think of formative and summative because you can only check if students are making progress or evaluate what they have achieved in relative to the curriculum objectives if you have known previously their starting points and skill levels. For the diagnostic, formative and summative assessment to bear good and lasting fruits, teachers or educators conducting them must apply some necessary techniques and special tools.

\section{Assessment Strategies and Tools}

Before delving into different assessment strategies and tools, it will be good to give brief explanation of the terms strategies and tools. Cooper delineate assessment tool as any device that help an assessor such as teacher or students to assess the quality of a given task or performance; some examples of assessment devices include rubrics, checklists, and scoring guides et cetera. Assessment strategies involve actual tasks and performances that students are required to undertake. Some examples include projects, assignments, tests, role-plays, debates, drama, quizzes, journal log, mind map, word web, essays, and conference. It is also worthy of mention to note that each assessment strategy has a purpose and specific assessment tool attached to it. Some assessment strategies and tools include

- Conference: to provide effective feedback on work done and to assess skills acquired such as reading, writing, speaking, comprehension and knowledge

Tool: Anecdotal record/Rubric

- Informal discussion: to assess depth of understanding and knowledge Tool: Anecdotal record/Rubric

- Oral questioning: to assess depth of understanding and knowledge Tool: Anecdotal record/Rubric

- Journal or learning log: to assess understanding and communication skills Tool: Rubric/checklist

- Designed project: to assess application of knowledge and skills acquired Tool: Checklist/Rubric

- Presentation: to assess understanding and communication skills Tool: Checklist/Rubric

- Role play: to assess understanding and communication skills Tool: Checklist/Rubric

- Quizzes/Tests consisting of selected response, short answer, extended response, multiple choice, matching, true or false, and fill in the blanks to assess knowledge and understanding Tool: scoring guide and marking scheme

- Mind map and word web: to assess depth of understanding, logical thinking, and organization Tool: Rubric

- Personal essay and review: to assess depth of understanding and knowledge Tool: Rubric/Checklist

\subsection{Benefits of Assessment Tools}

Assessment tools are very beneficial to both teachers and students. Teachers use them to gather and record information 
about how well a student is doing in a given task. Such data can be used for diagnostic, formative, or summative purposes. Designed assessment tools such as rubrics and scoring guides help each student to understand the standard and quality that is required of him or her for the assigned task. That is, students are well aware of the criteria that will be used to assess a given task, "as well as 'how good is good enough' for each of these criteria" (Cooper 2010). Tools such as checklist will help students include all the required elements before submitting their work for marking. Rubrics and anchors enable students know the learning targets they are striving to reach. They also help to improve the teachers' assessment and make it more reliable.

In addition to the already said benefits of assessment tools, I will like to add that the provision of assessment tools such as rubric, scoring guide, and checklist for an assigned task will maximize students' productivities. In order words, students will produce and very much and high quality work because there is no confusion as to what to do or what is expected of them in a given assignment. With checklist, a student can easily assess him/herself to see if his/her work contains all the essential elements. Checklist helps teacher to verify if a student has exhibited specific or required skills in his/her performance tasks. In contrast, students will produce a very little and poor quality work without good assessment tools and clear direction given to them. They can become easily frustrated, and may think of quitting the task or school as an alternative.

\subsection{Advantages and Disadvantages of Assessment Tools}

It is important to note that assessment tools have some advantages and disadvantages as well. For example, anecdotal record provides detailed information to teachers, students and parents, but is very time consuming. Checklist makes expectations clear to students, makes self and peer assessment easier, informs student about deficits in their task, but does not tell them how they can improve in their learning. Rubric "clarifies for teachers, students, and parents what quality work looks like" (Cooper), but can limit the range of student performance when poorly designed. I will also add that checklist and rubric can limit students' creativity. Hence, it is essential that teacher let students know that they are not limited to the checklist and rubric only. They can be as creative as possible, widening their horizons and adding any more important information they wish to add. Having represented some concepts, goals, purpose, types of assessment and assessment strategies and tools, it is deemed appropriate to discuss some of the teachers' roles for the authentic A\&E for the maximization of teaching and learning.

\section{Teachers' Duties during Authentic Assessment/Evaluation}

In a nutshell, it is a teacher's responsibilities to assess students before, during and after a specific period in learning. For example, he/she should assess his/her students at the beginning of a subject to know their prior knowledge and mindset. He/she will develop his/her lessons based upon her/his findings. He/she will adapt his/her lessons as needs arise and assess them using some techniques such as observation, conferencing or one-on-one discussion, quizzes, assignments, oral and written tests, homework assignments, in-class presentations, self and peer evaluation, journal log, portfolio, rubrics, projects, etc., and give students descriptive and frequent feedbacks on their strong and weak areas.

It is a teacher's duty to provide effective feedback on areas of improvements by giving students clear and specific direction about what they need to do differently to improve the quality of their work and performance. Feedback informs a student of how close he/she is to the knowledge or skills he/she is striving to develop. It also informs student of the steps to take in order to move to the next level. Brookhart (2008) argues that "feedback is only effective when it translates into a clear, positive message that students can hear." She also suggests different ways teachers can give effective feedback. During formative assessment, a teacher should give effective and descriptive feedback that promote learning, and shows students things they are doing well, gaps that need to be filled, and how those gaps will be filled up. McTighe and O'Connor maintained that feedback must be prompt in order to help the learner to improve and to promote learning; it must be "timely, specific, understandable to the receiver, and formed to allow self-adjustment on the student's part" (cited in Wiggins, 1998).

Another teacher's duty is the needs to treat students equitably and at the end of the term or year, or prescribed period, he/she will do summative assessment based on the data he/she has collected, artefacts or quality of the works produced using letter grades or numbers. It is the duty of teachers to be flexible in their assessment so as to help all students learn and experience success.

Another teacher's role is to help students find answers to five questions already posed in the assessment for learning namely "Where are we now? Where are we going and how do we get there from here? What and what made it 
possible for us to arrive where we are and what have we achieved?

\subsection{Examples of Teachers' Duties during Assessment Period}

Some examples of teachers' duties during assessment period include the following points: In terms of observing student(s) engaged in meaningful tasks, it is the duty of a teacher to make the following observations or notations using possible questions as follows: are the student(s) staying on task or on given topic? Have they grasped the topic, or does the teacher need to give further instruction or re-teach the topic? Do students need extra time for the task or can they do the task in another way? What curriculum outcomes are they achieving in what they are doing? Are they applying their prior knowledge or making use of their already learned skills or making personal connections, and depicting genuine understanding of the topic? (Cullen, 2012)

In one-on-one discussion or encounter, a teacher should check whether students make use of appropriate content terminology, ask significant questions, explain his/her work and give reasons for the choice of procedure he/she has made, show evidence of understanding what he/she is doing, show connection to the personal or prior knowledge and express alternative perspective towards the topic or given task. It is very important that teacher checks, while collecting students' work, whether individual students made use of the rubrics that was provided for the task or assignment. If yes, whether he/she meets the criteria, demonstrates understanding, makes use of the corrections the teacher gave during observation or one-on-one discussion. That is, whether the student made use of the feedback provided for him/her by the teacher. Also the teacher ought to check whether there is need to re-teach the topic to the entire class or to some students. Teachers have also responsibility of following or having rubrics for their assessment and evaluation.

\subsubsection{Rubrics of Assessement/Evaluation}

It is part of teachers' duty to produce A \& $E$ that is fair, equitable, of high quality, convincing or reliable. In a situation where students are honest and hardworking during classes, examination or test should be a continuation of what the class is doing or has done. Hence, exam/test period must not be a moment of torture, agony, fear, anxiety, panic, and frustration for students. Exams or tests should be made in such a way that if students remember them, they will be happy and looking forward to do them as opposed to having nightmares because of exams.

It is teachers' responsibility to ensure that A\&E are in line with the curriculum outcomes or learning targets, including what the teacher has taught, grading, and reporting process. Teachers' should see that assessment strategies and assessment tools match the task that is being assessed and the expected standards. In other words, teachers need to use appropriate assessment strategies and tools when assessing a piece of work. Teachers must try to make a balanced assessment by making use of oral, performance tasks, and written tasks.

It should be obligatory for teachers' to make an assessment that is triad. That is, it must involve the teacher, self or student, and peers so that students can take ownership of their learning, or be held accountable for their learning. Based on my assessment philosophy, a teacher needs to take the following steps to make his/her A\&E more prolific, authentic and valid. At the beginning of the semester or course, he/she should provide for students the following information: he/she should give to students a course outline or scheme for the term which will include the learning outcomes and expected standards. He/she ought to let his/her students know how they will be assessed and evaluated. Hence, from the onset of the class or lecture, students will know that the teacher or instructor expects a high quality work and not just quantity from them.

Finally, a teacher should let his/her students know that he/she will treatment them equitably and not equally. I agree with Guskey (2003) on his opinion of giving a second chance to help students demonstrate success in their learning. He maintains that "assessments cannot be a one shot, Do or die experience for students." Hence, I will add that those who need a second chance, extension of time for a given project, or extra time during quizzes, tests, and exams will get them if need be. This will give students opportunity to show their new skills or level of proficiency and comprehension. One might argue that second chance business will make students become lazy with their work. There is no doubt about that, but I will leave every teacher to make rightful decision on this issue. An adage says that out of the two evils, it is better to choose the lesser one. Above and beyond, it can be a fallacy to believe that I have exhausted this topic. Nonetheless, having made honest effort to put some points across, including some teachers' responsibilities, regarding $A \& E$ for the maximization of teaching and learning it is now appropriate to make some recommendations on assessment and evaluation of both students and teachers for better teaching and learning process. 


\section{Recommendations}

I re-emphasize that authentic assessment and evaluation are vital means for the maximization of teaching and learning. Diagnostic, Formative, and Summative Assessments together with excellent teaching method, appropriate assessment strategies and tools are crucial if a comprehensive, valid, and reliable result of the students' progress, what they have learned and are able to do, must be achieved. To this effect, I make the following recommendations:

1. Government (both Federal and States) in conjunction with the Education Ministry must plan and map out General and Specific Curriculum Outcomes and supervise teachers to ensure correct implementation of these outcomes in their teaching, A\&E process.

2. Ministry of Education and School Boards should ensure that competent persons are employed for A\&E of teaching and learning in schools.

3. Principals, Deans, and Heads of Departments of schools should be well grounded in the knowledge of A\&E methods so as to guide the teachers under their charge since a blind person cannot lead another blind person, else both will fall into a pit to the detriment of students and nations.

4. Education Ministers must make sure that every school has copies of state's or federal curriculum and School administrators (Principals, Deans, and Heads of department) must consult curriculum and ensure that classroom teachers consult and implement both general and specific outcomes in the planning, preparing their lessons and A\&E.

5. All teachers should take courses on A\&E during their teacher education program on how to use rubrics when assigning works for their students. This will provide guide line for students to enable them produce a high quality work because when they know what is expected of them, they will do better job.

6. States and School Boards or Administrators should provide in-service training or education workshops for teachers already in the teaching field, and make it mandatory because experience has shown that many teachers may not want to stress or stretch themselves to the widening of their horizons and up-grading themselves with the current practices.

7. Teachers should be taught during teacher training/education appropriate ways of giving regular and effective feedback to students in their A\&E process.

8. Assessment strategies and policies must be systematic and consistent at all levels of education in order to provide students with solid and sound education foundation that will carry them through in their future career.

9. Assessment must be both quantitative and qualitative and must not be done at superficial level. Teachers must assess students' previous and current knowledge before starting to teach them. He/she needs to show criteria and models of his/her expectations of students in a given assignment or project in advance. He/she should use summative assessments to frame meaning performance goals and allow appropriate choices to students.

10. In classrooms, teachers should neither lay too much emphasis on particular subjects more than the others nor look down on students that take certain subjects, but should help students see that all subjects are important and valid depending on one's gifts and talents.

11. Schools, at all levels, should have school guiding counsellor(s) to enable students make correct choice for the course of their study.

12. Parents must stop putting much pressure on their children about what they want them to become, but should consider first the ability of each child and encourage him/her to pursue his or her gift and talent.

The art of teaching and learning without regular and authentic assessment and evaluation is a useless or aimless exercise. Hence, I insist that diagnostic, formative, and summative assessments are indispensible if a comprehensive, valid, and reliable result of high teaching quality, the students' learning progress must be achieved. If A\&E are conducted properly and regularly, students of high academic quality will be produced. The nation will be enriched with people of high calibre and academic professional. Individuals will be fulfilled in life and nation will be developed in all aspects. As a result of good A\&E, best teachers, farmers, doctors, lawyers, engineers, musicians, artists, etc., will be produced for the nation's future consumption. Thus, there will be no "generation gap." A tradition of authentic assessment will continue from one generation to the other. The country will continue to have high qualified professionals who, in turn, will help to maintain very high quality of education standard nationwide. For any nation to continue to have high quality professionals and education standard, government, both state and federal, school administrators and teachers will have great role to play. The youths and children of our dear country, Nigeria, and other countries of the world will be transformed with the use of good assessment strategies and tools. Thus, diagnostic, formative and summative assessments are indispensible for effective teaching and learning. As I have already stated, I cannot really presume to have exhausted this topic 
because it is very vast. Therefore, what I have been able to produce is a contribution to what others have done and more people will still join to do more justice to enrich others on the importance of authentic assessment and evaluation for the maximization of teaching and learning and better ways to achieve it.

\section{References}

Brookhart, S. M. (2008). Informative Assessment in Educational Leadership, (65) 4, 54-59.

Cooper, D., Catania, J. (2010). Talk about assessment: High school strategies and tools. Ontario: Nelson Education Ltd.

Cullen, L. (2012). Evidence of Teaching, Evidence of Learning Retrieved from http://www.cea-ace.ca/blog/loricullen/2012/10/3/evidence-teaching-evidence-learning

Durkheim, E. (1973). Moral education. New York: The Free Press.

Fafunwa, A. B. (1991). History of education in Nigeria. Ibadan: NPS Educational Publishers Limited.

Federal Republic of Nigeria (2004). National Policy on Education 4th Edition

Guskey, T. R. (2003). How Classroom Assessment Improve Learning in Educational Leadership, (60)5, p.

http://www.utschools.ca/utseducation/assessmentandevaluation.aspx

http://www.utschools.ca/utseducation/assessmentandevaluation.as

http://duke.edu/arc/documents/The\%20difference\%20between\%20assessment\%20and\%20evalu ation.pdf:

McTighe, J., O'Connor, K. (2005). Seven Practices for EffectiveLearning in Educational Leadership, (63)3, p. 10-17.

Plato. Apology, trans. G.M.A. Grube.Pp. 112.130 in Readings in Ancient Greek Philosophy.Retrieved

Thales to Aristotle, 2nd ed. Indianapolis: Hackett Publishing Company, 2000, Paragraph 37e.

Sternberg, 1994 as cited in Guskey T. R., (2003). How Classroom Assessment improve learning in Educational Leadership, (60)5

Wiggin, G. (1992). Educative assessment: Designing assessment to inform and improve student performance. San Francisco: JosseyBass. 